\title{
FUZZY MULTI-OBJECTIVE APPROACH FOR THE IMPROVEMENT OF DISTRIBUTION NETWORK EFFICIENCY BY CONSIDERING DG
}

\author{
Ramadoni Syahputra \\ Department of Electrical Engineering, Faculty of Engineering, \\ Universitas Muhammadiyah Yogyakarta, Yogyakarta, 55183, Indonesia \\ ramadons @ymail.com
}

\begin{abstract}
This paper presents a fuzzy multi-objective approach for achieving the minimum active power loss and the maximum voltage magnitude in order to improve the efficiency of radial distribution networks with distributed generations. Multi-objective function are considered for load balancing among the feeders, minimization of the real power loss, deviation of nodes voltage, and branch current constraint violation, while subject to a radial network structure in which all loads must be energized. Originality of the research is that the fuzzy-based multi-objective optimization in reconfiguration of distribution network including the distributed generation in order to improve the efficiency of the networks. The implementation of the fuzzy multi-objective for distribution reconfiguration on a 70 nodes distribution network with distributed generation is described. The original efficiency of the network is $95.142 \%$. The simulation results show that efficiency of the network is increased to $96.942 \%$ by using fuzzy multiobjective method.
\end{abstract}

\section{KEYWORDS}

Fuzzy Logic, Multi-objective, Distribution Networks, Efficiency, Distributed Generations.

\section{INTRODUCTION}

Electrical power distribution system is one of the main elements in electrical power system. Nowadays, we are mostly dependent on energy from fossil fuels that have been a major cause of pollution and climate change. Therefore, finding and using renewable energy sources is becoming increasingly urgent. Perhaps the greatest challenge in realizing a sustainable future is to develop technology for integration and control of renewable energy sources in smart grid distributed generation (DG). DG is typically defined as small generators, less than 10-MW, commonly powered by renewable energy sources that are connected to transmission or distribution systems [1]. The great demands of renewable energy resources with respect to energy reserve and environmental issues make the new technologies such as fuel cells, photovoltaics, wind farms, and other resources more and more popular [2]. The government of Indonesia has targeted that DGs from renewable energy resources will be on-grid for up to $5 \%$ by the year 2025 [3]. Installation of DGs in electrical power distribution network creates a variety of well-documented impacts in with voltage rise, which is the dominant effect distribution system in rural networks [4-7]. Traditional options to mitigate adverse impacts remain costly for developers and Distribution Network Operators. With the increasing levels of generation to be accommodated, planning and design of distribution networks will need to change to harness approaches that use information and communication technology to actively manage the network (e.g., network reconfiguration [8]). 
Electrical power distribution systems have switches to configure the networks. There are two types of switch in the system, tie switch and sectionalizing switch, whose states determine the configuration of distribution network. Reconfiguration of the network is built through switching operation on switches of distribution network nodes. In modern power distribution systems, the multiple-objective feeder reconfiguration problem has assumed significant importance. The multiple objectives are considered for load balancing among the feeders and minimize the active power loss, while subject to a radial network structure in which all loads must be energized. Distribution networks are configured radially. Their configurations may be varied with manual or automatic switching operations so that the loads are supplied at the cost of possible minimum resistive line losses, increase system security and enhance power quality. Reconfiguration also reduces and relieves the overloading of the network feeders. The change in network configuration is performed by opening or closing of tie-switches and sectionalizing-switches of the network. These switching are performed in order to maintain the radially of the network with regard to all the loads are energized.

Many researches in literature have been focused for loss reduction with reconfiguration of distribution networks [9]. Reconfiguration of distribution network with aim for loss reduction was first proposed by Merlin and Back [10]. They have used a branch and bound type optimization technique to determine the minimum loss configuration. In this method, all network switches are first closed to form a meshed network. The switches are then opened successively to restore radial configuration. After that, many algorithms that aim to reduce the power loss of distribution system. Zhou et al. [11] have proposed two algorithms for reconfiguration of distribution network in order to service restoration and load balancing. Their methodologies were using combination of heuristic rules and fuzzy logics in optimization purposes for efficiency and robust performance. An optimization method to determine the network configuration with minimum energy losses for a given period has proposed by Taleski and Rajicic [12]. Borozan and Rajakovic [13] have considered the application aspects of optimal distribution network reconfiguration. Lin and Chin [14] have presented an algorithm of network reconfiguration using voltage index, ohmic index, and decision index to determine the switching operation. Jeon et al. [15] and Augugliaro et al. [16] have proposed artificial-intelligence-based applications in a minimum loss reconfiguration. Nara et al. [17] have proposed network reconfiguration techniques for minimum loss using a genetic algorithm (GA).

Das [18] have proposed an algorithm based on the fuzzy multi-objective approach for optimizing distribution network configuration. The four objectives load balancing among the feeders, real power loss, deviation of nodes voltage, and branch current constraint violation are modeled and results obtained are encouraging, but criteria for selecting a membership function for each objective are not provided. The use of harmony search algorithm (HSA) for optimal network reconfiguration of large-scale distribution system has presented by Rao et al. [19]. The algorithm is a technique which is conceptualized using the musical process of searching for harmony in perfect state. It uses a stochastic random search instead of a gradient search which eliminates the need for derivative information.

In this research, the formulations of the distribution network reconfiguration problem as a multiple objectives problem subject to operational and electric constraints are performed. The problem formulations presented herein consider four different objectives related to: minimization of the system's active power loss; minimization of the deviation of nodes voltage; minimization of the branch current constraint violation; and load balancing among various feeders. Radially of the network must remain after reconfiguration in which all loads must be simultaneously energized. These four objectives are modeled with fuzzy sets. Heuristic rules are also incorporated in the algorithm for minimizing the number of tie-switch operations. The objective of this research is to show that the fuzzy multi-objective can be used successfully in 
the reconfiguration of electrical distribution networks with distributed generation to minimize the active power losses and to balance the loading of the feeders in order to improve efficiency of the networks.

\section{FuzZy Multi-OBJECTIVE Method}

The fuzzy multi-objective method in this paper has developed by Das [18]. In domain of fuzzy system, each objective is associated with a membership function. The membership function refers the degree of satisfaction of the objective. In the crisp domain, either the objective is satisfied or it is violated, implying membership values of unity and zero, respectively. On the contrary, fuzzy sets entertain varying degrees of membership function values from zero to unity. Thus, fuzzy set theory is an extension of standard set theory. When there are multiple objectives to be satisfied simultaneously, a compromise has to be made to get the best solution. The four objectives described in this research are first fuzzified. After that, the results of the fuzzification are integrated into a fuzzy satisfaction objective function $\mathrm{J}$ through appropriate weighting factors. In the proposed method for network reconfiguration, the terms $\mathrm{m}_{\mathrm{Li}}, \mathrm{m}_{\mathrm{Vi}}, \mathrm{m}_{\mathrm{Ai}}$ and $\mathrm{m}_{\mathrm{Bi}}$ indicate the membership function for real power loss reduction, maximum node voltage deviation, maximum branch current loading index and load balancing of the feeders, respectively. The higher membership value implies a greater satisfaction with the solution. The membership functions in fuzzy system that consists of a lower and upper bound value are described below.

\subsection{Membership Function for Active Power Loss Reduction}

The most important assignment in order to increase the efficiency of distribution network is minimization of the active power loss. Therefore, the aim of the constructing of fuzzy membership function is to reduce the active power loss of the system. Let us define

$$
x_{i}=\frac{P_{\text {loss }(i)}}{P_{l o s s(0)}}, \text { for } i=1,2,3, \ldots, N_{k}
$$

where, $\mathrm{N}_{\mathrm{k}}$ is the total number of branches in the loop including tie-branch, when i-th tie-switch is closed, $\mathrm{P}_{\text {loss }}(\mathrm{i})$ is the total real power loss of the radial configuration of the system when $\mathrm{i}$-th branch in the loop is opened, and $\mathrm{P}_{\text {loss }}(0)$ is the total real power loss before network reconfiguration.

From equation (1) can be expressed that if $x_{i}$ is high, power loss reduction is low and, hence, a lower membership value is assigned and if $x_{i}$ is low, the power loss reduction is high and a higher membership value is assigned.

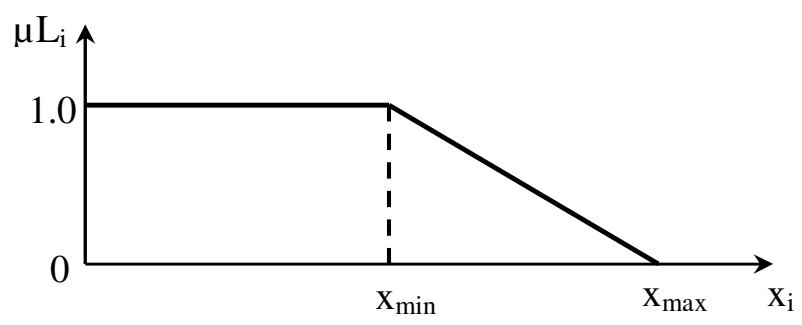

Figure 1. Membership function for power-loss reduction. 
The membership function for real power loss reduction is given in Figure 1. From Figure 1, $\mu_{\mathrm{Li}}$ can be written as

$$
\begin{aligned}
& \mu L_{i}=\frac{\left(x_{\max }-x_{i}\right)}{\left(x_{\max }-x_{\text {min }}\right)}, \text { for } x_{\text {min }}<x_{i}<x_{\max } \\
& \mu L_{i}=1, \text { for } x_{i} \leq x_{\min } \\
& \mu L_{i}=0, \text { for } x_{i} \leq x_{\max }
\end{aligned}
$$

In this research, it has been assumed that $x_{\min }=0.5$ and $x_{\max }=1$. This means if the loss is $50 \%$ or less of the $\mathrm{P}_{\text {loss }}(0)$, the unity membership value is assigned and if the loss is $100 \%$ or more of $\mathrm{P}_{\text {loss }}(0)$, the zero membership value is assigned.

\subsection{Membership Function for Maximum Node Voltage Deviation}

The aim of the constructing of this membership function is that the deviation of nodes voltage should be less. Let us define

$$
y_{i}=\max \left|V_{i, j}-V_{s}\right|, \quad \text { for } i=1,2,3, \ldots, N_{k} \text { and } j=1,2,3, \ldots, N B .
$$

where, $N_{k}$ is total number of branches in the loop including the tie branch, when the i-th tie switch is closed; NB is total number of nodes of the system; $\mathrm{V}_{\mathrm{s}}$ is voltage of the substation (in per unit); and $\mathrm{V}_{\mathrm{i}, \mathrm{j}}$ is voltage of node corresponding to the opening of the $\mathrm{i}$-th branch in the loop (in per unit).

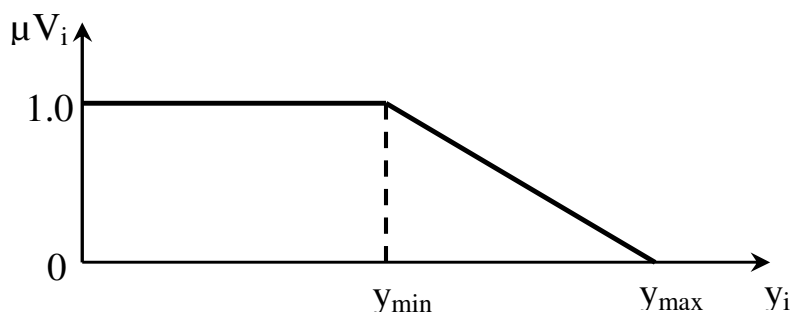

Figure 2. Membership function for voltage deviation.

In fuzzy environment of the research, if the maximum voltage deviation is less, then a higher membership value is assigned and if deviation is more, then a lower membership value is assigned. Figure 2 shows the membership function for maximum node voltage deviation. From Figure 2, we can write

$\mu V_{i}=\frac{\left(y_{\max }-y_{i}\right)}{\left(y_{\text {max }}-y_{\text {min }}\right)}$, for $y_{\text {min }}<y_{i}<y_{\text {max }}$

$\mu V_{i}=1, \quad$ for $y_{i} \leq y_{\min }$

$\mu V_{i}=0$, for $y_{i} \leq y_{\max }$

In this research, $\mathrm{y}_{\min }=0.05$ and $\mathrm{y}_{\max }=0.10$ have been considered. $\mathrm{y}_{\min }=0.05$ means if the substation voltage is 1.0 p.u., then the minimum system voltage will be 0.95 p.u. and if the minimum system voltage is greater than or equal to 0.95 p.u., the unity membership value is assigned. Similarly, if $\mathrm{y}_{\max }=0.10$, the minimum system voltage will be 0.90 p.u. and if the minimum system voltage is less than or equal to 0.90 p.u., the zero membership value is assigned. 


\subsection{Membership Function for Maximum Branch Current Loading Index}

The basic purpose for this membership function is to minimize the branch current constraint violation. Let us define

Branch current loading index $=\frac{|I(i, m)|}{I_{c}(m)}$, for $i=1,2,3, \ldots, N_{k}$, and $m=1,2,3, \ldots, N B-1$.

where, $\mathrm{N}_{\mathrm{k}}$ is total number of branches in the loop including the tie branch when the $\mathrm{i}$-th tie switch is closed; $|\mathrm{I}(\mathrm{i}, \mathrm{m})|$ is magnitude of current of branch-m when the $\mathrm{i}$-th branch in the loop is opened; $\mathrm{I}_{\mathrm{c}}(\mathrm{m})$ is line capacity of branch-m; NB is total number of the nodes of the system.

Let us define

$z_{i}=\max \left[\frac{I(i, m)}{I_{c}(m)}\right], \quad$ for $i=1,2,3, \ldots, N_{k}$, and $m=1,2,3, \ldots, N B-1$

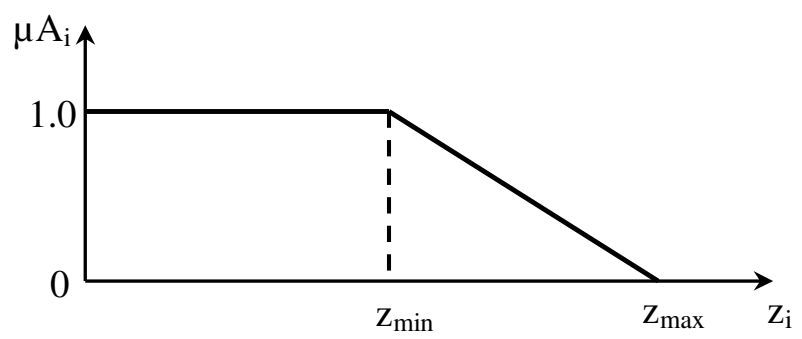

Figure 3. Membership function for current loading index.

When the maximum value of branch current loading index exceeds unity, a lower membership value is assigned and as long as it is less than or equal to unity, the maximum membership value is assigned (i.e., unity). The membership function for the maximum branch current loading index is shown in Figure 3. From Figure 3, we can write

$$
\begin{aligned}
& \mu A_{i}=\frac{\left(z_{\max }-z_{i}\right)}{\left(z_{\max }-z_{\min }\right)}, \text { for } z_{\min }<z_{i}<z_{\max } \\
& \mu A_{i}=1, \quad \text { for } z_{i} \leq z_{\min } \\
& \mu A_{i}=0, \quad \text { for } z_{i} \leq z_{\max }
\end{aligned}
$$

In this research, $\mathrm{z}_{\min }=1.0$ and $\mathrm{z}_{\max }=1.15$ have been considered. $\mathrm{z}_{\min }=1.0$ indicates that as long as the branch currents of the system are less than or equal to their respective line capacity, unity membership value is assigned and $\mathrm{z}_{\max }=1.15$ indicates that $15 \%$ overloading is allowed for each branch and if in any branch, the current is greater than or equal to 1.15 times the line capacity, a zero membership value is assigned.

\subsection{Membership Function for Feeder Load Balancing}

Load balancing is one of the major objectives of feeder reconfiguration. An effort to increase the loading margin of heavily loaded feeders of distribution system is to transfer part of their loads to lightly loaded feeders. Feeder load balancing index may be given as 
$F L B_{i, j}=\frac{\left(I F F_{i, \text { max }}-I F_{i, j}\right)}{I F F_{i, \text { max }}}$, for $i=1,2,3, \ldots, N_{k}$, and $j=1,2,3, \ldots, N F$.

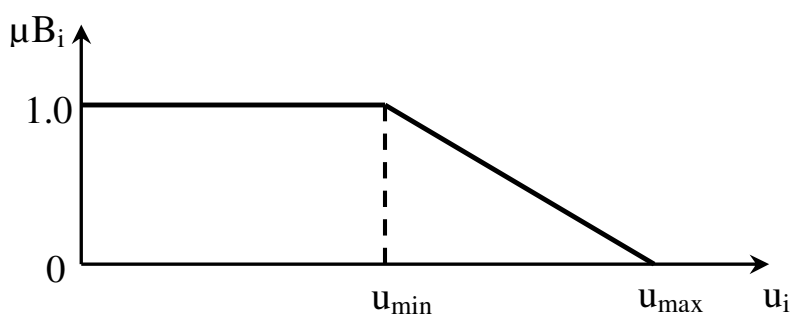

Figure 4. Membership function for the load balancing index.

where, $\mathrm{N}_{\mathrm{k}}$ is total number of branches including the tie branch in the loop when the the switch is closed; NF is total number of feeders; $\mathrm{IF}_{\mathrm{i}, \mathrm{j}}$ is current of feeder corresponding to the opening of the th branch in the loop; $\mathrm{IFF}_{\mathrm{i}}, \mathrm{max}$ is is the maximum of all the feeder currents corresponding to the opening of the $i$-th branch in the loop $=\max \left(\operatorname{IF}_{i, j}\right)$, for $j=1,2,3, \ldots, N F$.

Let us define

$u_{i}=\max \left(F L B_{i, j}\right), \quad$ for $i=1,2,3, \ldots, N_{k}$, and $j=1,2,3, \ldots, N F$

Equation (9) indicates that a better load balancing can be achieved if the value of $u_{i}$ is low. Therefore, for lower $\mathrm{u}_{\mathrm{i}}$, a higher membership grade is assigned and for higher $\mathrm{u}_{\mathrm{i}}$, a lower membership grade is assigned. Figure 4 shows the membership function for ui. From Figure 4, we can write

$\mu B_{i}=\frac{\left(u_{\max }-u_{i}\right)}{\left(u_{\max }-u_{\text {min }}\right)}$, for $u_{\text {min }}<u_{i}<u_{\text {max }}$

$\mu B_{i}=1$, for $u_{i} \leq u_{\text {min }}$

$\mu B_{i}=0, \quad$ for $u_{i} \leq u_{\max }$

In this case, $\mathrm{u}_{\min }=0.10$ and $\mathrm{u}_{\max }=0.50$ have been considered. $\mathrm{u}_{\min }=0.10$ indicates that the maximum deviation of feeder currents will be $10 \%$ with respect to the maximum value of feeder current and if this deviation is less than or equal to $10 \%$, the unity membership value is assigned and $\mathrm{u}_{\max }=0.50$ indicates that if this deviation is greater than $50 \%$, a zero membership value is assigned.

\subsection{Fuzzy Multi-objective Algorithm}

A fuzzy multi-objective algorithm for the network reconfiguration process in order to improve efficiency of the distribution network is given below:

Step 1) Read system data;

Step 2) Run the load-flow program for distribution networks;

Step 3) Compute the voltage difference across the open tie switches (i.e., $\Delta V_{\text {iie }}(l)$ for i $=$ $1,2, \ldots$, n-tie); 
Step 4) Identify the open tie switch across which the voltage difference is maximum and its code k (i.e., $\Delta V_{\text {tiemax }}=\Delta V_{\text {tie }}(k)$;

Step 5) If $V_{\text {tie, } m a x}>\varepsilon_{z}$ go to Step 6); otherwise, go to Step10);

Step 6) Select the tie switch "k" and identify the total number of loop branches $\left(\mathrm{N}_{\mathrm{k}}\right)$ including the tie branch when the tie-switch " $\mathrm{k}$ " is closed;

Step 7) Open one branch at a time in the loop and evaluate the membership value for each objective and also evaluate the overall degree of satisfaction (i.e., for $\mathrm{i}=1$ to $\mathrm{N}_{\mathrm{k}}$, compute $\mu_{\mathrm{Li}}, \mu_{\mathrm{Vi}}, \mu_{\mathrm{Ai}}$, and $\mu_{\mathrm{Bi}}$ using (2), (4), (7), and (10), respectively, and evaluate: $\mathrm{D}_{\mathrm{k}, \mathrm{i}}=\min \left\{\mu_{\mathrm{Li}}, \mu_{\mathrm{Vi}}, \mu_{\mathrm{Ai}}, \mu_{\mathrm{Bi}}\right\}$

Step 8) Obtain the optimal solution for the operation of tie-switch "k", (i.e., $O_{S k}=\max \left\{D_{k, i}\right\}$, for $\mathrm{i}=1,2, \ldots, \mathrm{N}_{\mathrm{k}}$ );

Step 9) Rearrange the coding of the rest of the tie switches and go to Step 2);

Step 10) Print output results;

Step 11) Stop.

\section{Test Case}

In order to show the efficiency of the described method, we have tested the $11-\mathrm{kV}$ radial distribution system having two substations, four feeders, 70 nodes, and 78 branches (including tie branches) as shown in Figure 5. This network has two substations, topologically connected by a repartition node. Tie switches of this system are open in normal conditions. Figure 5 shows the initial configuration of distribution network without distributed generations. The optimization of reconfiguration of distribution network with distributed generation using fuzzy multi-objective was implemented in Matlab, and the simulations were performed on an Intel Pentium ${ }^{\circledR}$ core(TM) 2 duo CPU, $1.80 \mathrm{GHz}, 4$ GB RAM.

Before reconfiguration the network, the total active power loss of this system is $227.510 \mathrm{~kW}$. In this original condition, efficiency of distribution network is $95.142 \%$. The minimum voltage magnitude that occurs in bus of 67 is 0.900 p.u., as shown in Figure 6. In this work, we have installed seven distributed generations (DGs) in nodes of 3, 6, 24, 29, 38, 52, and 64, respectively, as shown in TABLE I. From the result of our case study, it can be seen from the 70-node test system that DG has the effects of loss reduction improvement over feeders in this particular case. The total active power loss of this system with DGs is $156.206 \mathrm{~kW}$, or, the efficiency of distribution network is $96.633 \%$, as shown in TABLE II. The minimum voltage magnitude that occurs in node of 67 is 0.913 p.u., as shown in Figure 7.

Table 1. Installation Node and Capacity of DG

\begin{tabular}{|c|c|c|}
\hline Node & Capacity $(\mathbf{k W})$ & Power Factor \\
\hline 3 & 50 & 0.8 \\
\hline 6 & 100 & 0.9 \\
\hline 24 & 200 & 0.9 \\
\hline 29 & 100 & 1 \\
\hline 38 & 200 & 0.9 \\
\hline 52 & 50 & 0.8 \\
\hline 64 & 100 & 0.9 \\
\hline
\end{tabular}




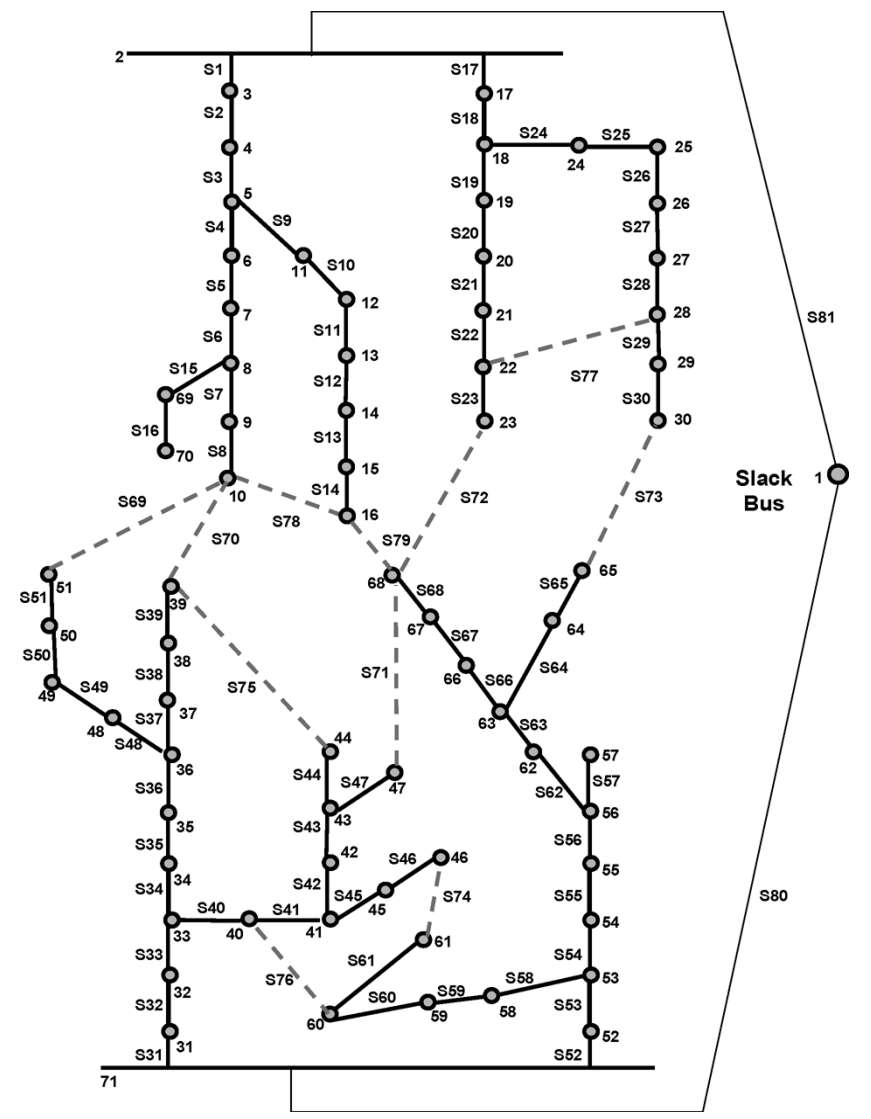

Figure 5. A 11-kV radial distribution system [20].

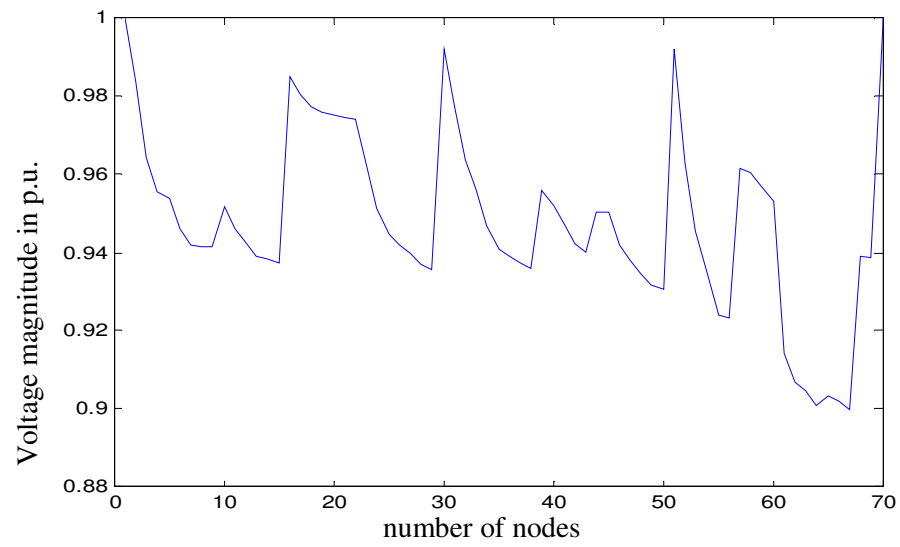

Figure 6. Voltage profiles for each nodes of distribution network without DG before reconfiguration. 
After reconfiguration, the total active power loss is $141.239 \mathrm{~kW}$, or the other words, the efficiency of distribution network is $96.942 \%$, as shown in TABLE II. The minimum voltage magnitude is 0.937 p.u. that occurs in node of 15 . Figure 8 shows the voltage profiles for each nodes of distribution network with DG after reconfiguration.

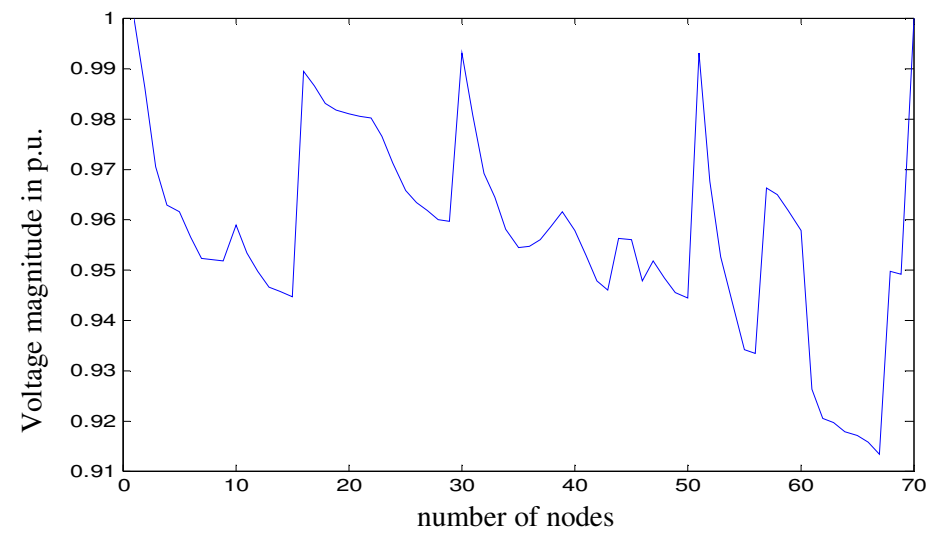

Figure 7. Voltage profiles for each nodes of distribution network with DG before reconfiguration.

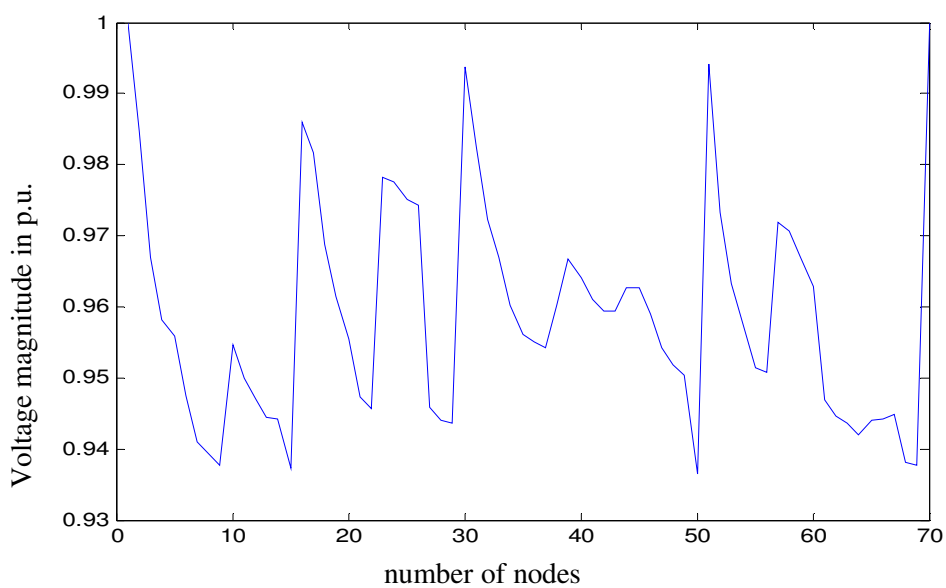

Figure 8. Voltage profiles for each nodes of distribution network with DG after reconfiguration.

Figure 9. shows distribution of power loss for each node of distribution network before reconfiguration, while Figure 10 shows distribution of power loss for each node of distribution network after reconfiguration. It is observed that the losses in almost every branch is reduced, except at $4,6,7,11,16,18,19$, and 20 , where the losses are increased because of shifting of loads onto these feeders.

From the result of our case study, it can be seen from the 70 nodes radial distribution system test system that DG has the effects of loss reduction improvement over feeders in this particular case, and the topological structures of optimum network without DG are different from those with DG. 
International Journal of Computer Science \& Information Technology (IJCSIT) Vol 4, No 2, April 2012

Table 2. The Results of Simulation of 70 Nodes Distribution Network

\begin{tabular}{|l|c|c|c|}
\hline \multirow{2}{*}{ Test Case } & \multicolumn{3}{|c|}{ Parameters of Analysis } \\
\cline { 2 - 4 } & $\begin{array}{c}\text { Active Power } \\
\text { Loss (kW) }\end{array}$ & $\begin{array}{c}\text { Efficiency of } \\
\text { Distribution } \\
\text { Network (\%) }\end{array}$ & $\begin{array}{c}\text { Minimum } \\
\text { Voltage (p.u.) }\end{array}$ \\
\hline $\begin{array}{l}\text { Distribution network } \\
\text { without DG before } \\
\text { reconfiguration }\end{array}$ & 227.510 & 95.142 & $0.900\left(\mathrm{~V}_{67}\right)$ \\
\hline $\begin{array}{l}\text { Distribution network } \\
\text { with DG before } \\
\text { reconfiguration }\end{array}$ & 156.206 & 96.633 & $0.913\left(\mathrm{~V}_{67}\right)$ \\
\hline $\begin{array}{l}\text { Distribution network } \\
\text { with DG after } \\
\text { reconfiguration }\end{array}$ & 141.239 & 96.942 & $0.937\left(\mathrm{~V}_{15}\right)$ \\
\hline
\end{tabular}

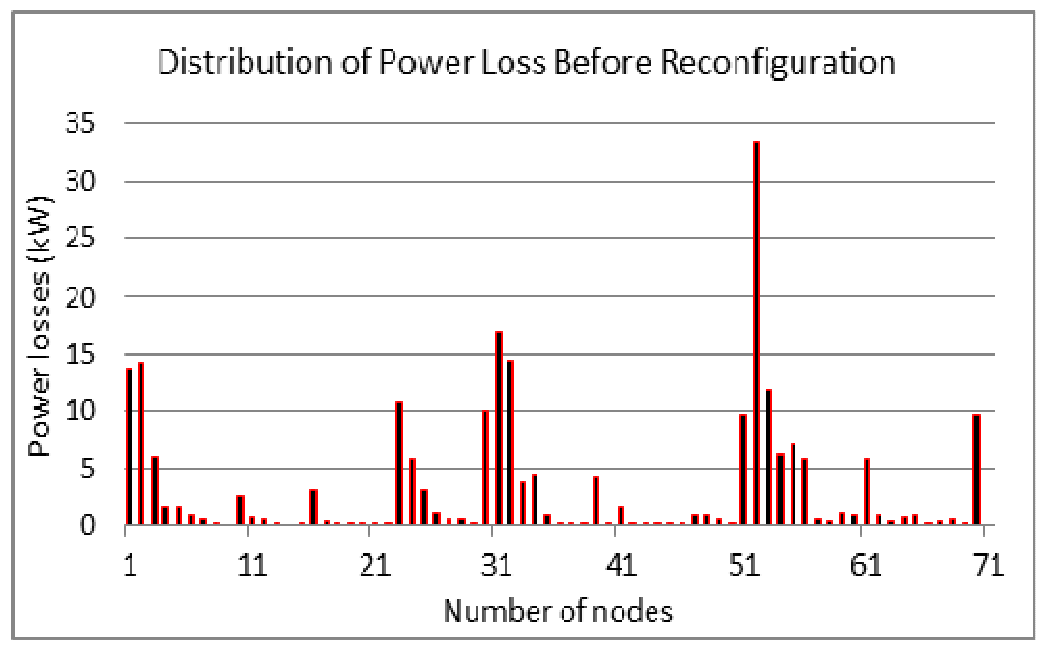

Figure 9. Distribution of power loss before reconfiguration.

Based on the 70 nodes radial distribution system with DG, the presented method in this paper has significant loss reduction in order to improve the efficiency of distribution system with distributed generation (DG).

The presented method has not been compared with other methods, since, by the author's knowledge, there are no similar methods suitable for comparison in the case of 70 nodes distribution network with distributed generation (DG). 


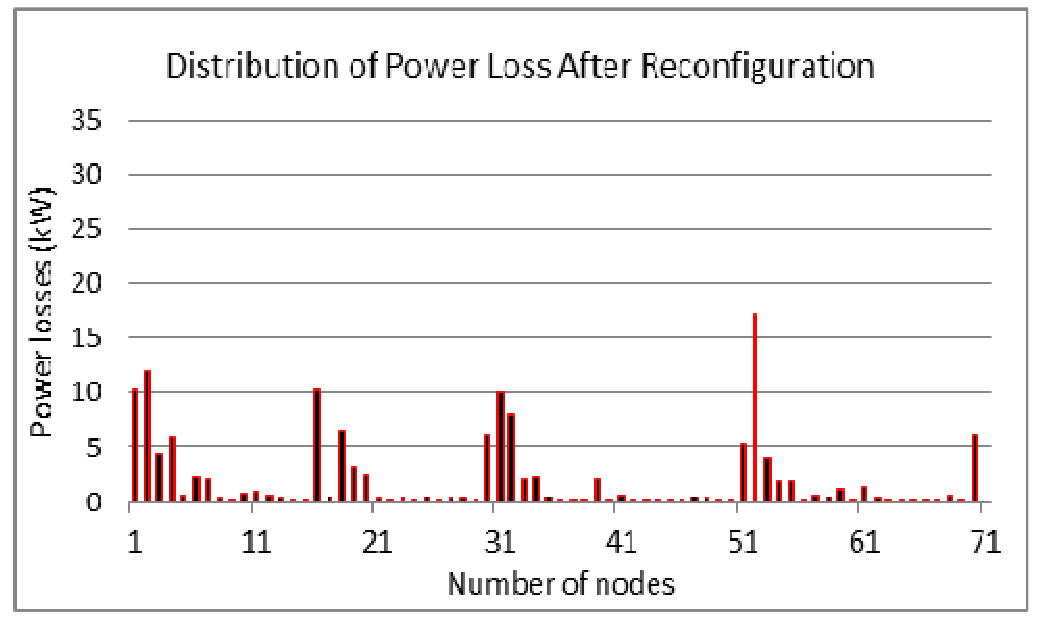

Figure 10. Distribution of power loss after reconfiguration.

\section{Conclusions}

A fuzzy-based methodology for optimal reconfiguration of distribution networks by considering distributed generation in order to improve efficiency of the networks has been presented in this paper. The effectiveness of the method has been demonstrated by a 70-node distribution network test system. The main advantage of the presented method is the capabilities of reducing the active power losses and increasing the voltage magnitude of nodes of distribution network. From the results of this paper, it can be seen that DGs has the improvement effects on loss reduction and can increase the voltage magnitude of distribution system. The simulation results show that efficiency of the network is increased from $95.142 \%$ (before reconfiguration, without DGs) to $96.942 \%$ (after reconfiguration, with DGs) by using fuzzy multi-objective method.

\section{ACKNOWLEDGEMENTS}

The author is gratefully acknowledge the contributions of the Directorate General of Higher Education (DIKTI), Ministry of Education and Culture, Republic of Indonesia, for funding in this research under Competitive Research Grant (Program Penelitian Hibah Bersaing), Number of Contract: 560.5/K5/KL/2012.

\section{REFERENCES}

[1] A.M. Borbely and J.F. Kreider, (2001), "Distributed Generation: The Power Paradigm for the New Millennium”, CRC Press, Washington D.C.

[2] K. Zou, A.P. Agalgaonkar, K.M. Muttaqi, and S. Perera, (2012), Distribution System Planning With Incorporating DG Reactive Capability and System Uncertainties, IEEE Transactions On Sustainable Energy, Vol. 3, No. 1, January 2012, pp. 112-123.

[3] D. Kusdiana, (2008), "Kondisi Riil Kebutuhan Energi di Indonesia dan Sumber-Sumber Energi Alternatif Terbarukan", Presented at the Seminar of Renewable Energy, Direktorat Jenderal Listrik dan Pemanfaatan Energi Departemen Energi dan Sumber Daya Mineral, Bogor, 3 Dec. 2008.

[4] S. Civanlar, J. J. Grainger, H. Yin, and S. S. H. Lee, (1988), "Distribution Feeder Reconfiguration for Loss Reduction," IEEE Trans. Power Del., vol. 3, no. 3, pp. 1217-1223.

[5] M. E. Baran and F. F.Wu,(1989), "Network Reconfiguration in Distribution Systems for Loss Reduction and Load Balancing," IEEE Transaction on Power System, vol. 4, no. 3, pp. 1401-1407. 
[6] L.F. Ochoa and G.P. Harrison, 2011, Minimizing Energy Losses: Optimal Accommodation and Smart Operation of Renewable Distributed Generation, IEEE Transactions on Power Systems, Vol. 26, No. 1, February 2011, pp. 198-205.

[7] W.C. Wu and M.S. Tsai, 2011, Application of Enhanced Integer Coded Particle Swarm Optimization for Distribution System Feeder Reconfiguration, IEEE Transactions on Power Systems, Vol. 26, No. 3, August 2011, pp. 1591-1599.

[8] C. S. Chen and M. Y. Cho, (1993), "Energy Loss Reduction by Critical Switches," IEEE Trans. Power Delivery, vol. 8, no. 3, pp. 1246-1253.

[9] V. Borozan, D. Rajicic, and R. Ackovski, (1995), "Improved Method for Loss Minimization in Distribution Networks," IEEE Transaction on Power System, vol. 10, no. 3, pp. 1420-1425.

[10] A. Merlin and H. Back, (1975), "Search for a minimal-loss operating spanning tree configuration in an urban power distribution system," in Proc. 5th Power System Computation Conf., Cambridge, U.K., 1975, pp. 1-18.

[11] Q. Zhou, D. Shirmohammadi, and W. H. E. Liu, (1997), "Distribution Feeder Reconfiguration for Service Restoration and Load Balancing,” IEEE Trans. Power Syst., vol. 12, no. 2, pp. 724-729.

[12]R. Taleski and D. Rajicic, (1997), "Distribution Network Reconfiguration for Energy Loss Reduction," IEEE Transaction on Power System, vol. 12, no. 1, pp. 398-406.

[13] V. Borozan and N. Rajakovic, (1997), “Application Assessments of Distribution Network Minimum Loss Reconfiguration,” IEEE Transaction on Power Delivery, vol. 12, no. 4, pp. 1786-1792.

[14] W. M. Lin and H. C. Chin, (1998), “A New Approach for Distribution Feeder Reconfiguration for Loss Reduction and Service Restoration," IEEE Transaction on Power Delivery, vol. 13, no. 3, pp. 870-875.

[15] Y. J. Jeon, J. C. Kim, J. O. Kim, J. R. Shin, and K. Y. Lee, (2002), “An Efficient Simulated Annealing Algorithm for Network Reconfiguration in Large-Scale Distribution Systems," IEEE Transaction on Power Delivery, vol. 17, no. 4, pp. 1070-1078.

[16] A. Augugliaro, L. Dusonchet, M. Ippolito, and E. R. Sanseverino, (2003), "Minimum Losses Reconfiguration of MV Distribution Networks Through Local Control of Tie-Switches," IEEE Transaction on Power Delivery, vol. 18, no. 3, pp. 762-771.

[17] K. Nara, A. Shiose, M. Kitagawa, and T. Ishihara, (1992), "Implementation Of Genetic Algorithm for Distribution System Loss Minimum Reconfiguration," IEEE Transaction on Power Delivery, vol. 7, no. 3, pp. 1044-1051.

[18]D. Das, (2006), “A Fuzzy Multi-Objective Approach for Network Reconfiguration of Distribution Systems,” IEEE Transaction on Power Delivery, vol. 21, no. 1, pp. 202-209.

[19] R.S. Rao, S.V.L. Narasimham, M.R. Raju, and A.S. Rao, (2011), “Optimal Network Reconfiguration of Large-Scale Distribution System Using Harmony Search Algorithm", IEEE Transactions on Power Systems, Vol. 26, No. 3, pp. 1080-1088.

[20]B. Enacheanu, B. Raison, R. Caire, O. Devaux, W. Bienia, and N. HadjSaid, (2008), "Radial Network Reconfiguration Using Genetic Algorithm Based on the Matroid Theory", IEEE Transactions on Power Systems, Vol. 23, No. 1, pp. 186-195.

\section{Author}

Ramadoni Syahputra was born in Deli Serdang, North Sumatera, Indonesia, on October 10, 1974. He received B.Sc. degree from Institut Teknologi Medan and M.Eng. degree from Department of Electrical Engineering, Universitas Gadjah Mada, Yogyakarta, Indonesia in 2002. His research interests are in computational of power system, artificial intelligence in power system, power system control, application of fuzzy logic in power system, distributed generation, and renewable energy.

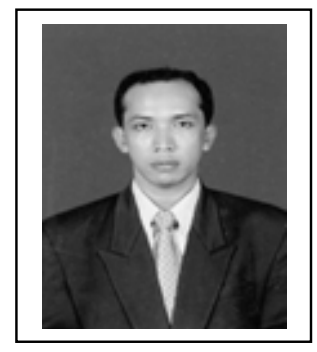

